\title{
Risk Factors for Gestational Diabetes Mellitus
}

\author{
Zinat Begum, ${ }^{1}$ Dewan Shahida Banu, ${ }^{2}$ Shaila Sharmeen Shanta, ${ }^{3}$ Shitil Ibna Islam ${ }^{4}$
}

\begin{abstract}
Objective: The present study was undertaken to determine the risk factors for Gestational Diabetes Mellitus (GDM) presented at Bangladesh Institute of Research in Diabetes, Endocrine \& Metabolic Disorders (BIRDEM).

Materials \& methods: The present case-control study was conducted at BIRDEM Hospital, Dhaka over a period of 6 months from July to December 2011. A total of 100 pregnant women (20 cases and 80 controls) were consecutively enrolled in the study. Pregnant women who developed diabetes at their $3^{\text {rd }}$ trimester were cases $(n=20)$, while pregnant women free from diabetes at their $3^{\text {rd }}$ trimester were controls $(n=80)$. The diagnosis of GDM was made using a two-step approach. Pregnant women were initially screened by measuring the plasma glucose concentrations 1 hour after a 50 gram of oral glucose challenge. A diagnostic oral glucose tolerance test was performed on the subset of women whose plasma glucose concentrations exceded the threshold value for glucose ( $>140 \mathrm{mg} / \mathrm{dl}$ ).
\end{abstract}

Result: The study showed that older patients ( $\geq 25$ years) were predominant in both case and control groups. The groups were almost comparable in terms of socioeconomic status and occupation. The distribution of gestational age was also similar between groups (33.1 \pm 6.3 vs. $34.2 \pm 3.9$ years, $p=0.476)$. Majority $(85 \%)$ of the cases had family history of diabetes $(p<0.001)$. Thirty five percent of cases were nulipara and $65 \%$ multipara compared to $51.3 \%$ and $48.7 \%$ respectively of the control $(p=0.076)$. No significant difference was observed between the groups in terms of preterm labour and PROM ( $p=0.690$ and 0.220 respectively). Forty percent of cases had past history of GDM compared to $3.8 \%$ of controls $(p<0.001$ ). The fasting plasma glucose and plasma glucose $2 \mathrm{hrs}$ after $75 \mathrm{~g}$ of glucose ingestion were significantly higher in pregnant women having GDM than those in normal pregnant women $(8.3 \pm 3.1$ vs. $4.1 \pm 0.5 \mathrm{mmol} / \mathrm{L}, \mathrm{p}<0.001 ; 12.9 \pm 4.8$ vs. $5.9 \pm$ $1.2 \mathrm{mmol} / \mathrm{L}, \mathrm{p}<0.001$ respectively).

Conclusion: The study concluded that none of the sociodemographic characteristics like age, socioeconomic status and occupation was found to be associated with GDM. However, pregnant women with family history of diabetes are at risk of developing GDM significantly more than those without GDM. Multipara tend to develop GDM more frequently than the primipara does. Past incidence of GDM increases the risk of GDM in the subsequent pregnancy.

Key words: Risk factors, gestational diabetes.

\section{INTRODUCTION}

Gestational diabetes mellitus (GDM) is defined as any degree of glucose intolerance with onset or first recognition during pregnancy. It occurs in 5 $10 \%$ of all pregnancies. ${ }^{1}$ Classical risk factors for developing gestational diabetes are maternal age (older than 35 years of age), history of type 2 diabetes in first degree relatives, a previous diagnosis of gestational diabetes or prediabetes or impaired glucose tolerance or overweight and obesity, a previous pregnancy which resulted in a child with a high birth weight $\left(>90^{\text {th }}\right.$ centile, or $>4$ $\mathrm{kg}){ }^{1}$

Epidemiologic characteristics of gestational diabetes were assessed in an ethnically diverse cohort of 10,187 women who had undergone standardized screening for glucose intolerance and who delivered a singleton infant at the Mount

\section{Authors' information:}

${ }^{1}$ Dr. Zinat Begum, Assistant Professor, Department of Gynae \& Obstetrics, Dhaka Medical College, Dhaka.

${ }^{2}$ Dr. Dewan Shahida Banu, Assistant Professor (Obstetrics \& Gynaecology), DGO, FCPS, Shaheed Tazuddin Ahmad Medical College, Gazipur.

${ }^{2}$ Dr. Shaila Sharmeen Shanta, Research Investigator, International Centre for Diarrhoeal Disease Research, Bangladesh (icddr,b), Dhaka.

${ }^{3}$ Shitil Ibna Islam, Research Officer, Ibrahim Cardiac Hospital \& Research Institute, Shahbag, Dhaka.

Correspondence: Dr. Zinat Begum, Cell phone: +880 1745-79854. 
Sinai Medical Center in New York City between January 1987 and December 1989. The overall prevalence of gestational diabetes was $3.2 \%$. Multiple logistic regression analysis showed excess risks for Orientals, first generation Hispanics, women from the Indian subcontinent and the Middle East. The older, heavier and poorer women and those with a positive family history of diabetes were also at higher risk of developing GDM than their respective counterparts. ${ }^{2}$ Serum ferritin concentration has been thought to be a risk factor of GDM and studies have shown a significant relation between higher serum ferritin levels and insulin resistance syndrome and risk of type 2 diabetes. ${ }^{3-5}$ In Chinese pregnant women, serum ferritin concentration was higher in women with impaired glucose tolerance and GDM. ${ }^{6,7}$

As gestational diabetes mellitus increases the risk of macrosomia and perinatal morbidity and mortality for the fetus, while presaging a long-term risk of developing type 2 diabetes for the mother, ${ }^{8,9}$ identifying the risk factors is of utmost significance in preventing the onset of GDM at least to some extent. Survey of the existing literatures revealed that there is paucity of studies regarding risk factors for GDM in the context of our population. The proposed study would facilitate a better understanding of the risk factors for developing GDM.

\section{MATERIALS \& METHODS}

This case-control study was conducted over a period of 6 months between July to December 2011 at BIRDEM Hospital, Dhaka. Pregnant women at their third trimester with gestational diabetes were selected as cases $(n=20)$. The diagnosis of GDM was made using a two-step approach. Pregnant women were initially screened by measuring the plasma glucose concentrations 1 hour after a $50 \mathrm{gram}$ of oral glucose challenge. A diagnostic oral glucose tolerance test was performed on the subset of women whose plasma glucose concentrations exceeded the threshold value for glucose (> $140 \mathrm{mg} / \mathrm{dl}$ ). Pregnant women at their third trimester without gestational diabetes were included as control $(n=80)$. Data were processed and analysed using software SPSS (Statistical Package for Social Sciences) version 16.0. The test statistics used to analyse the data were descriptive statistics, Chi-square $\left(x^{2}\right)$ Test, Student's t-Test. The level of significance was set at 0.05 and $p$-value $<0.05$ was considered significant.

\section{RESULTS}

The cases were generally older ( $70 \%$ were $\geq 25$ years old) compared to controls ( $53 \%$ were $\geq 25$ years old). The occupation and socioeconomic status were almost comparable between the case and control groups $(p=0.735$ and $p=0.870$ respectively). Majority ( $85 \%$ ) of the cases had family history of diabetes as compared to $33.8 \%$ of the controls $(p<0.001)$. Forty percent of the cases were obese compared to $38.8 \%$ of controls $(p=0.918)$ (Table $I)$. There was no significant difference between the cases and controls in terms of clinical characteristics like anaemia, jaundice, oedema and haemodynamic variables like pulse, systolic and diastolic blood pressures ( $p>0.05)$ (Table II).

The gestational age was homogeneously distributed between case and control groups (33.1 \pm 6.3 vs. $34.2 \pm 3.9$ years, $p=0.476$ ). Thirty five percent of cases were nulipara and $65 \%$ multipara which in control group were $51.3 \%$ and $48.7 \%$ respectively $(p=0.076)$. No significant difference was noted between the groups in terms of preterm labour and PROM ( $p=0.690$ and 0.220 respectively) (Table III). Forty percent of cases had past history of gestational diabetes mellitus compared to $3.8 \%$ of controls ( $p<0.001$ ). Past history of still-birth or IUD was found in $5 \%$ of controls, which in the case group was completely absent (Table IV). Biochemical investigations of the patients demonstrated that the fasting plasma glucose and plasma glucose $2 \mathrm{hrs}$ after $75 \mathrm{~g}$ of glucose load were significantly higher in case group than those in control group $(8.3 \pm 3.1$ vs. $4.1 \pm 0.5 \mathrm{mmol} / \mathrm{L}, \mathrm{p}<0.001 ; 12.9 \pm 4.8$ vs. 5.9 $\pm 1.2 \mathrm{mmol} / \mathrm{L}, \mathrm{p}<0.001$ respectively) (Table $\mathrm{V}$ ). 


\begin{tabular}{|c|c|c|c|}
\hline \multirow[b]{2}{*}{ Variables* } & \multicolumn{2}{|c|}{ Group } & \multirow[b]{2}{*}{$\mathrm{p}$-value } \\
\hline & $\begin{array}{c}\text { Case } \\
(n=20)\end{array}$ & $\begin{array}{l}\text { Control } \\
(n=80)\end{array}$ & \\
\hline \multicolumn{4}{|l|}{ Age (years) } \\
\hline$<25$ & $6(30.0)$ & $37(46.3)$ & \multirow{2}{*}{0.189} \\
\hline$\geq 25$ & $14(70.0)$ & $43(53.8)$ & \\
\hline \multicolumn{4}{|l|}{ Occupation } \\
\hline Housewife & $14(70.0)$ & $59(73.8)$ & \multirow{2}{*}{0.735} \\
\hline Service & $6(30.0)$ & $21(26.3)$ & \\
\hline \multicolumn{4}{|c|}{ Socioeconomic status } \\
\hline Lower class & $3(15.0)$ & $13(16.3)$ & \multirow{3}{*}{0.870} \\
\hline Middle class & $17(85.0)$ & $66(82.5)$ & \\
\hline Rich & $0(0.0)$ & $1(1.3)$ & \\
\hline \multicolumn{4}{|c|}{ Family $\mathrm{H} / \mathrm{O}$ diabetes } \\
\hline Present & $17(85.0)$ & $27(33.8)$ & \multirow{2}{*}{$<0.001$} \\
\hline Absent & $3(17.0)$ & $53(66.2)$ & \\
\hline \multicolumn{4}{|l|}{ BMI $\left(\mathrm{kg} / \mathrm{m}^{2}\right)$} \\
\hline Normal $(<25)$ & $12(60.0)$ & $49(61.3)$ & \multirow{2}{*}{0.918} \\
\hline Obese $(\geq 25)$ & $8(40.0)$ & $31(38.8)$ & \\
\hline
\end{tabular}

*Chi-square $\left(\chi^{2}\right)$ Test was employed to analyse the data. Figures in the parenthesis denote corresponding $\% ; \chi^{2}$ Test was employed to analyse the data.

\begin{tabular}{|lccc|}
\hline TABLE II. Comparison of clinical characteristics between groups \\
\hline Clinical characteristics & \multicolumn{3}{c}{ Group } \\
& $\begin{array}{c}\text { Case } \\
(\mathrm{n}=20)\end{array}$ & $\begin{array}{c}\text { Control } \\
(\mathrm{n}=80)\end{array}$ & $\mathrm{p}$-value \\
\hline Anaemia* & $1(5.0)$ & $11(13.8)$ & 0.281 \\
Jaundice** & $1(5.0)$ & $00-$ & \\
Oedema* & $7(35.0)$ & $14(17.5)$ & 0.086 \\
Pulse\# & $78 \pm 6$ & $78 \pm 7$ & 0.949 \\
Systolic BP\# & $117 \pm 12$ & $112 \pm 16$ & 0.288 \\
Diastolic BP\# & $68 \pm 19$ & $72 \pm 11$ & 0.169
\end{tabular}

*Chi-square $\left(\chi^{2}\right)$ Test was employe to analysed the data.

\# Data were analysed using Student's t Test and were presented as mean \pm SD.

**Fisher's Exact Test was done to analyzed the data.

TABLE III. Comparison of current pregnancy profile between groups

\begin{tabular}{lccc} 
Current pregnancy profile & \multicolumn{2}{c}{ Group } & \\
& $\begin{array}{c}\text { Case } \\
(n=20)\end{array}$ & $\begin{array}{c}\text { Control } \\
(n=80)\end{array}$ & p-value \\
Gestational age & $33.1 \pm 6.3$ & $34.2 \pm 3.9$ & 0.476 \\
Parity & & & \\
$\quad$ Nulipara & $7(35.0)$ & $41(51.3)$ & 0.076 \\
$\quad$ Multipara & $13(65.0)$ & $39(48.7)$ & \\
Preterm labour* & $4(20.0)$ & $13(16.3)$ & 0.690 \\
PROM* $^{*}$ & $5(25.0)$ & $11(13.8)$ & 0.220
\end{tabular}

*Chi-square $\left(\chi^{2}\right)$ Test was employed to analyse the data.

\# Data were analysed using Student's t Test and were presented as mean \pm SD.
TABLE IV. Comparison of past obstetric history between groups

\begin{tabular}{lccc} 
Past obstetric history & \multicolumn{2}{c}{ Group } & \\
& Case & Control & p-value \\
& $(n=20)$ & $(n=80)$ & \\
History of GDM* & $8(40.0)$ & $3(3.8)$ & $<0.001$ \\
H/O still born/lUD** & 00 & $4(5.0)$ & -
\end{tabular}

*Chi-square $\left(\chi^{2}\right)$ Test was employed to analyse the data.

**Fisher's Exact Test was done to analyzed the data.

TABLE V. Comparison of past obstetric history between groups

\begin{tabular}{|c|c|c|c|}
\hline \multirow[b]{2}{*}{ Biochemical parameters" } & \multicolumn{2}{|c|}{ Group } & \multirow[b]{2}{*}{$p$-value } \\
\hline & $\begin{array}{c}\text { Case } \\
(n=20)\end{array}$ & $\begin{array}{l}\text { Control } \\
(n=80)\end{array}$ & \\
\hline Fasting plasma glucc & $8.3 \pm 3.1$ & $4.1 \pm 0.5$ & $<0.001$ \\
\hline Plasma glucose after $2 \mathrm{hrs}$ & $12.9 \pm 4.8$ & $5.9 \pm 1.2$ & $<0.001$ \\
\hline
\end{tabular}

\# Data were analysed using Student's $\mathbf{t}$ Test and were presented as mean \pm SD.

\section{DISCUSSION}

The present study has demonstrated that older patients ( $\geq 25$ years) and housewife were predominant in both case and control group. The socioeconomic status was almost comparable between case and control groups $(p=0.735)$. The gestational age was homogeneously distributed between case and control groups $(33.1 \pm 6.3$ vs. $34.2 \pm 3.9$ years, $p=0.476)$. The distribution of women was almost similar in terms of parity $(p=$ $0.076)$. Majority $(85 \%)$ of cases had family history of diabetes compared to controls $(33.8 \%)$ ( $p<$ 0.001 ). No significant difference was found between the groups in terms of preterm labour and PROM ( $p=0.690$ and 0.220 respectively). Two-fifth of the cases had past history of gestational diabetes mellitus compared to only $3.8 \%$ of controls $(p<0.001)$. Park et al. ${ }^{10}$ in an attempt to find the risk factors for GDM conducted a study on 266 pregnant women in their twenties to forties. Of them 91 women had GDM confirmed by $100 \mathrm{~g}$ oral glucose tolerance test (OGTT) and the rest 175 women did not have GDM and comprised the control group. The two groups did not differ with respect to their mean ages; but the mean pregestational body mass index (BMI), incidence of glycosuria and family history of DM were significantly higher in the GDM group than 
those in the control group. The past history of GDM, pregnancy induced hypertension and delivery of macrosmic baby were also considerably higher in the former group than those in the latter group. In a similar study by Cho et al ${ }^{11}$ elderly gravida, past history of intrauterine foetal death, perinatal death, preeclampsia, and GDM and family history of diabetes mellitus were revealed to be the risk factors of GDM.

Clinical detection of GDM is carried out to identify pregnancies at increased risk for perinatal morbidity and mortality. Available data do not identify a threshold of maternal glycemia at which such risk begins and increases rapidly. A multinational study, the hyperglycemia and adverse pregnancy outcome study is underway to explore this issue in a large multiethnic cohort. In the absence of a defined glucose threshold for perinatal risk, many different sets of glycemic criteria have been proposed and are employed worldwide for the diagnosis of GDM. The criteria currently recommended by the American Diabetes Association ${ }^{12}$ are based on O'Sullivan's criteria. The detection of GDM, a condition that is generally asymptomatic, involves screening in 2 sequential steps, followed by administration of a 2- or 3-hour OGTT to women determined to be at risk by screening. Women with very high clinical risk characteristics may be diagnosed with probable pregestational (preexisting) diabetes. When these diagnostic criteria for a 3-hour OGTT were applied to a group of Caucasian women in Toronto, approximately $7 \%$ had GDM. ${ }^{13}$

The frequency of GDM may vary among ethnic groups (higher in groups with increased prevalence of hyperglycemia) ${ }^{14}$ and with the use of different diagnostic criteria (higher when lower glucose thresholds are applied and vice versa). ${ }^{15}$ Nonetheless, all approaches to GDM detection pinpoint and thereby allow diagnosis of women with glucose tolerance in the upper end of the population distribution during pregnancy. A small minority of those women possesses glucose levels that would be diagnostic of diabetes outside of pregnancy. The great majority have lower glucose levels. Both groups impart to their offspring an increased risk of perinatal morbidity and long-term obesity and diabetes that appear to be related at least in part to fetal overnutrition in utero. They also incur for themselves a risk of diabetes after pregnancy.

A history of diabetes, previously reported as a useful risk criteria, ${ }^{16}$ was not assessed in the present study. It has been shown that, in the Maltese population, a history of diabetes in the pregnant women was significantly associated with a risk of GDM and IGT, besides subsequent risk of developing NIDDM in later life. ${ }^{17}$ The glucose challenge screening test is highly specific, for it usually does not miss women who have GDM.

\section{CONCLUSION}

The findings of the study demonstrated that none of the sociodemographic characteristics like age, socioeconomic status and occupation was found to be associated with GDM. However, pregnant women with family history of diabetes were at risk of developing GDM significantly more than those without having such history. Multiparas tend to develop GDM more than the primiparas do. Past incidence of GDM increases the risk of GDM in the subsequent pregnancies. Whatever factors to be associated with the development of GDM, screening should be done to reduce the incidence of adverse perinatal outcome.

\section{REFERENCES}

1. Carr DB, Gabbe S. Gestational Diabetes: Detection, Management, and Implications. Clinical Diabetes $1998 ; 16(1): 4$.

2. Gertrud SB, Robert HL, Wein R, Lee D. Race/Ethnicity and Other Risk Factors for Gestational Diabetes. Am J Epidemiol 1992;135:965-73.

3. Fernández-Real JM, Ricart W, Arroyo E, Balança R, Casamitjana $R$, Cabrero $D$ et. al. Serum ferritin as a component of the insulin resistance syndrome. Diabetes Care $1998 ; 21: 62-8$.

4. Tuomainen TP, Nyyssonen $\mathrm{K}$, Salonen $\mathrm{R}$, Tervahauta A, Korpela H, Lakka T et al. Body iron stores are associated with serum insulin and blood glucose concentrations: population study in 1,013 eastern Finnish men. Diabetes Care 1997;20:426-8. 
5. Fernandez-Real JM, Vayreda M, Richart C, Gutierrez C, Broch M, Vendrell J, Ricart W et. al. Circulating interleukin 6 levels, blood pressure, and insulin sensitivity in apparently healthy men and women. $J$ Clin Endocrinol Metab 2001;86:1154-9.

6. Lao T, Tam K-F. Maternal serum ferritin and gestational impaired glucose tolerance. Diabetes Care 1997;20:1368-9.

7. Lao $\Pi$, Chan LY, Tam K-F, Ho Lai-Fong. Maternal haemoglobin and risk of gestational diabetes mellitus in Chinese Women. Obstet \& Gynaecol 2002;99:807-12.

8. American Diabetes Association. Gestational diabetes mellitus. Diabetes Care 2002;23(Suppl 1):S77-S79.

9. Clark CM, Qiu C, Amerman B, Porter B, Fineberg N, Aldasouqi $S$ et al. Gestational diabetes: should it be added to the syndrome of insulin resistance? Diabetes Care 1997;20:867-71.

10. Park JH, Song HJ, Choun JK, Cho JJ, Paek YJ, Park KH et al. Risk factors for gestational diabetes mellitus. Korean J Obes $2005 ; 14: 178-85$.
11. Cho AR, Kyeung KS, Park MA, Lee YM, Jeong EH. Risk Factors of Gestational Diabetes Mellitus. Korean J Perinatol 2007;18(4):329-37.

12. American Diabetes Association. Diagnosis \& classification of diabetes mellitus. Diabetes Care 2004;27(Suppl. 1):S5-S10.

13. Naylor CD, Sermer M, Chen E, Sykora K. Cesarean delivery in relation to birth weight and gestational glucose tolerance: pathophysiology or practice style. JAMA 1996;275:1165-70.

14. Ben-Haroush A, Yogev Y, Hod M. Epidemiology of gestational diabetes mellitus and its association with Type 2 diabetes. Diabet Med 2004;21:103-13.

15. O Sullivan JB, Mahan CM. Criteria for the oral glucose tolerance test in pregnancy. Diabetes 1964;13:278-85.

16. Barden TP, Knowles HC. Diagnosis of diabetes in pregnancy. Clinical Obstet Gynecol 1981;24(1):3-19.

17. Savona-Ventura C, Gatt M. Embryonal risks in gestational diabetes mellitus. Early Hum Dev 2004;79(1):59-63. 